\title{
A METHOD FOR PREPARING LOCAL VOLUME TABLES
}

\author{
By D. E. NICKERSON
}

\author{
Dominion Forest Service
}

W HILE cruising in Temiscouata County, Province of Quebec, during the summer of 1936 I was confronted with the problem of preparing estimates for considerable quantities of northern white cedar. No local volume table or detailed studies of utilization requirements were available for this species. There was, therefore, a need for data based on local measurements which could be readily adjusted in the light of later studies of utilization and adapted to varying heights of stump and lengths of logs or bolts, variations in the minimum diameters of material desired, and to the measurement of piece products.

The method described in this article was developed to fulfill these conditions and although northern white cedar is the species considered in the example there is no apparent limit of species or type of product to which the method could be applied.

As the first step thirty trees were cut down. These were selected at random, included no obviously deformed specimens, and represented all diameter classes as evenly as possible. Next, the total height, the diameter at breast height outside bark (D.B.H.O.B.); the diameter at breast height inside bark (D.B.H.I.B.) and the diameter inside bark (D.I.B.) at each tenth height above breast height were measured. Diameters were measured to the nearest tenth inch and intermediate heights to the nearest tenth foot. This completed the field work.

As the first step in compilation, double bark thickness at breast height was compiled by D.B.H. classes and a smooth curve prepared to express this relation (Fig. 1).

Next the D.I.B. at each tenth height was expressed as a percentage of D.B.H.I.B. This information for all trees was grouped for each of the fractions of height and the averages plotted (Fig. 2) in the form D.I.B. in Per cent of D.B.H.I.B. over Height in Tenths above B.H. Despite the small number of measurements taken it was found that these plotted points showed prace tically no deviation from a smooth curve.

Thirdly a smooth curve was constructed showing the relation between Total Tree Height and D.B.H.O.B. In the construction of this curve Heights were averaged by D.B.H.O.B. classes (Fig. 3 ).

With this information it was found possible to chart the average form of trees in each D.B.H.O.B. class (Fig. 4). These curves show the relation between Height from Ground and D.I.B. at any point. The plotted points 
LOCAL VOLUME TABLES-NICKERSON
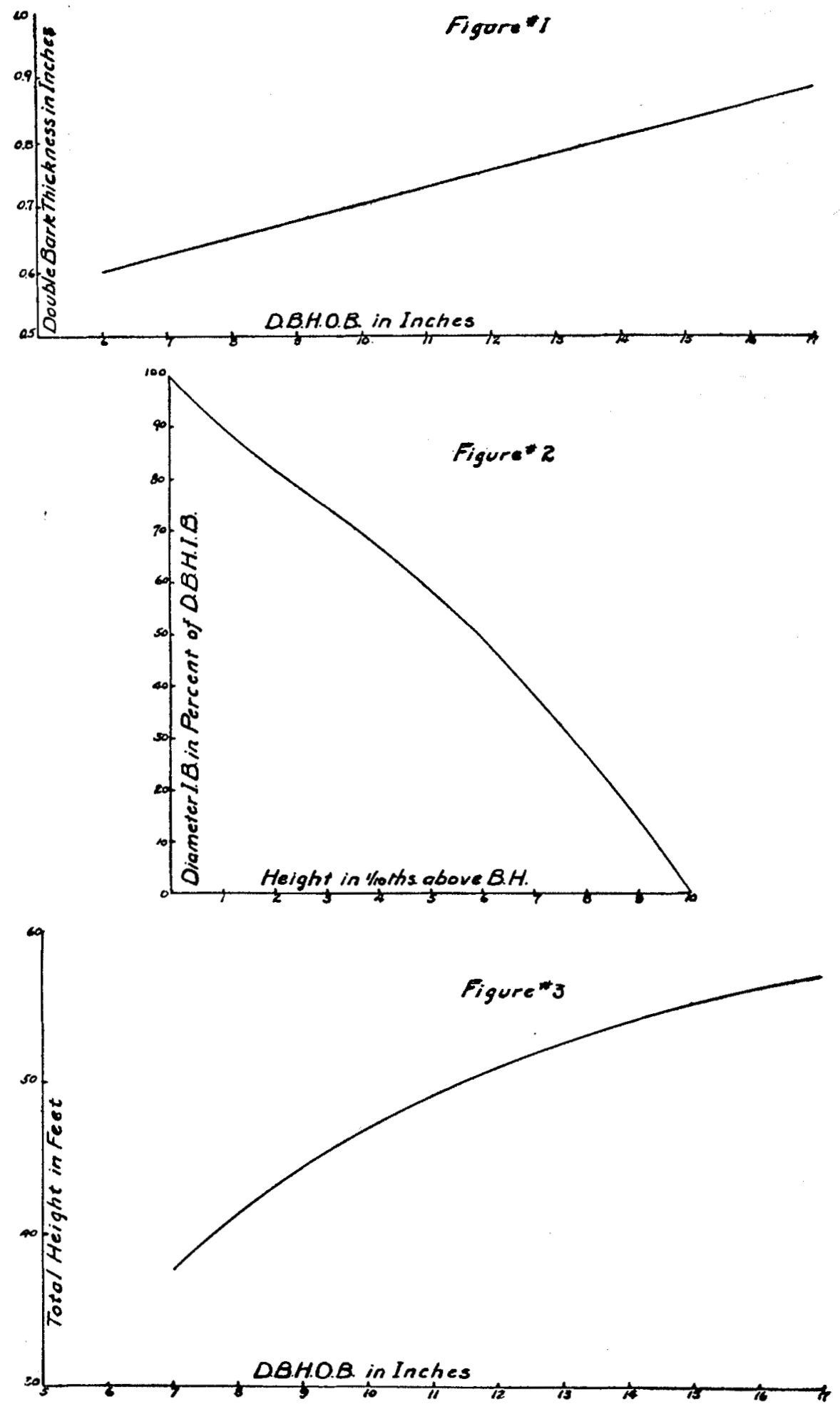

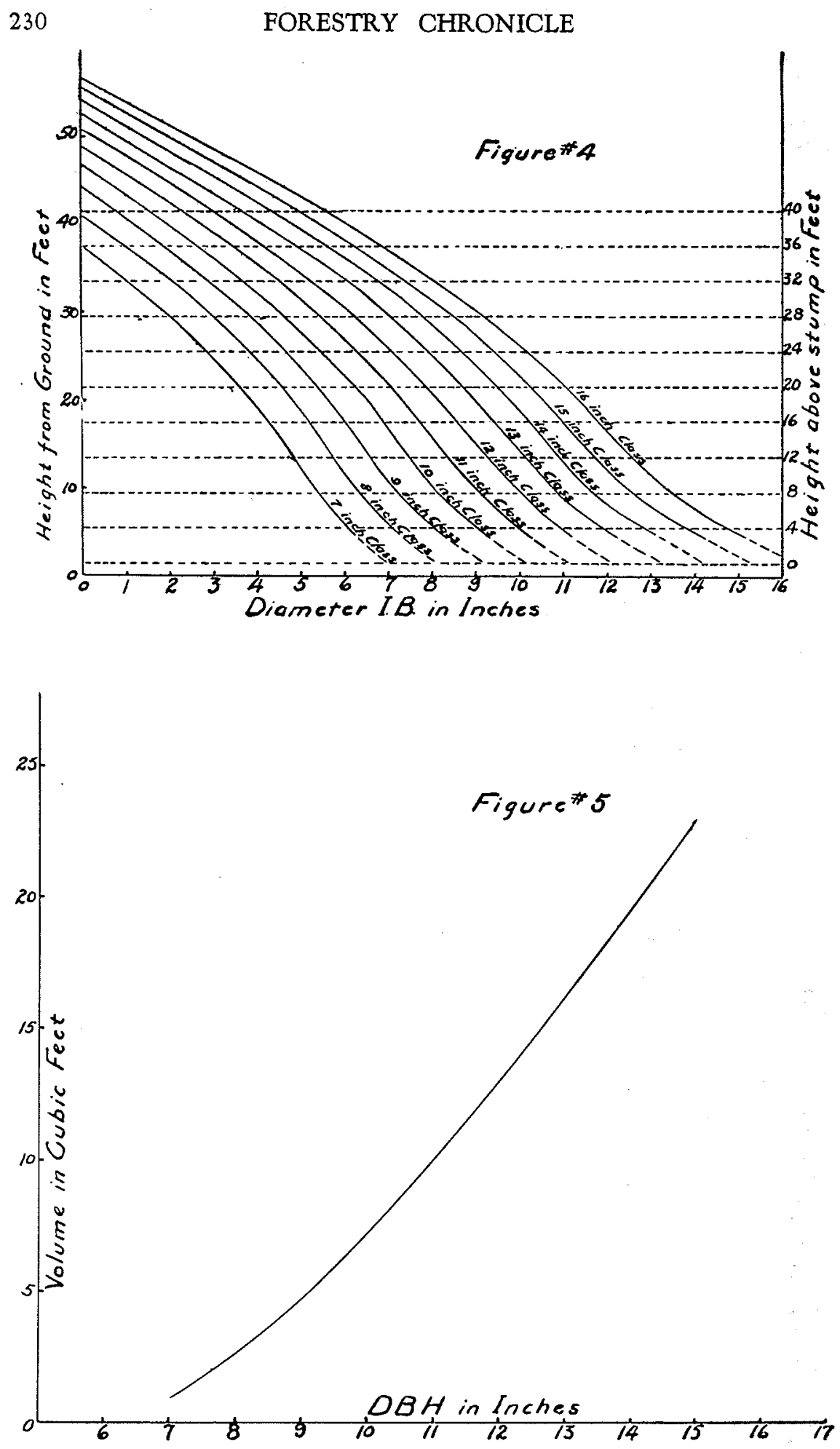
which were joined to give these curves were computed from Figs. 1, 2, and 3. An example is worked out here.

Example: For the eight-inch D.B.H.O.B. class.

Wanted: D.I.B. and height in feet at two-tenths height above breast height.

Fig. 1-Double bark thickness of an eight inch tree at breast height is 0.7 inches. Therefore D.B.H.I.B. is 7.3 inches.

Fig. 2-D.I.B. at two-tenths height is $81.5 \%$ of 7.3 or 6.0 inches.

Fig. 3-Actual height at two-tenths height is $4.5+2 / 10$ of 37 or 11.9 feet.

Therefore a tree eight inches in diameter at breast-height outside bark has a diameter of 6.0 inches inside bark at 11.9 feet from the ground.

Similar values were computed for each tenth height on trees of the eightinch D.B.H. class. These points were plotted and a smooth curve drawn through the points (Fig. 4). Similarly curves were drawn on the same graph for each D.B.H. class. Since the plotted points were computed from smooth curves it was found that there was almost no tendency for plotted points to deviate from their corresponding curves.

On this graph each curve was extended below breast-height, and horizontal lines were drawn at 1.5 feet and each four-foot interval above. The projection of the curves was felt justified here as a conservative treatment for butt swell, while the points at which the parallel lines intercept each of the curves indicate the diameters inside bark at those heights.

Fig. 5 is one of the final volume tables, and in this case it indicates what the volume in cubic feet of trees in each D.B.H. class would be if these trees were utilized in four-foot lengths, stump-height were 1.5 feet, and no bolts were cut with a top diameter less than six inches. The plotted points on this final graph are easily computed since from Fig. 4 the number of bolts and the end diameters of each may be read directly. The fitting of a smooth curve to these plotted points completes the preparation of the table.

To save confusion only one final volume relation has been shown, but if a detailed comparison of several standards and methods of utilization is desired an almost endless variety of tables may be prepared from Fig. 4 by varying stump heights, log lengths, minimum used diameters, types of product, units of measure, etc.

Since preparing this volume table several possible improvements have sug. gested themselves to me, among them:

(1) The actual measurement of diameter inside bark at stump height and incorporation of this information in Fig. 4 as a general guide.

(2) The possibility of supplementing the information on bark thickness in Fig. 1 by measurements of bark thickness at all measured diameters through. 
out the height of the trees. In other words, if on a ten-inch tree a measurement happened to fall at a point where the diameter outside bark was between 4.6 and 5.5 inches, then the double bark thickness at this point would be pooled with measurements of double bark thickness at breast-height on all trees in the five-inch D.B.H. Class.

(3) Supplementary measurements of the total height of standing trees could be used to advantage in Fig. 3.

(4) Possibly the number of points above breast-height at which measurements are taken could be reduced without sacrificing accuracy. Actually in the example given correlation was practically perfect, and the omission of one-half of the plotted points in Fig. 2 would have had no appreciable effect insofar as the location of the curve was concerned.

In conclusion it is pointed out that while no particular originality is claimed for any part of this method, the whole presents an economical and entirely independent way of determining for an individual area the number and actual dimensions of logs or piece products obtainable from average trees in each D.B.H. class. With this information as a basis volume tables may be readily prepared to suit actual requirements. 